\title{
Poroz Kanatçık İlaveli Hava Isıtmalı PV/T Kolektörünün Sürdürülebilirlik İndeksi ve Termodinamik Analizi
}

\author{
Fatih Bayrak \\ Siirt Üniversitesi, Mühendislik Fakültesi, Makine Mühendisliği Bölümü, 56100, Siirt, Türkiye \\ fatih.byrk@gamil.com \\ Makale gönderme tarihi:01.05.2021, Makale kabul tarihi: 05.10.2021
}

\begin{abstract}
$\ddot{O} \mathbf{z}$
Fotovoltaik panellerin ve güneş kolektörlerinin ayrı ayrı kullanılması hem maliyeti hem de kapladıkları alanı artırmaktadır. Bu yüzden araştırmacıları bir sistemden hem 1sı hem de elektrik üretmeye yönlendirmiştir. Bu deneysel çalışmada, yeni tip kanatçıklı hava ısıtmalı fotovoltaik/termal (PV/T) kolektör tasarlanmış ve karşılaştırılmalı olarak test edilmiştir. Deneylerde, kanatçıklı ve kanatçıksız PV/T kolektörlere doğal taşınım (DT) ve zorlanmış taşınım $\left(m_{1}=\right.$ $0.01 \mathrm{~kg} / \mathrm{s} \mathrm{ve} m_{2}=0.015 \mathrm{~kg} / \mathrm{s}$ ) uygulanmıştır. Tüm sistemlerin termodinamik analizi ve ekserji veriminin bir fonksiyonu olan sürdürülebilirlik indeksi (SI) incelenmiştir. Elde edilen sonuçlara göre kütlesel debinin artması ve kanatçık entegre edilmesi PV/T sisteminin çıkış gücüne, elektriksel enerjisine ve ekserjisine pozitif etki etmiştir. Sistemdeki en düşük çıış̧ gücü kanatçıksız ve doğal taşınımda (M1) $26.84 \mathrm{~W}$, en yüksek çıkış gücü kanatçıklı ve zorlanmış taşınımda (M6) 37.40W'tır. Tüm PV/T kolektörleri karşılaştırıldığında en yüksek genel ekserji verimi \%20.48 ile doğal taşınımlı ve kanatçıklı M4 kolektörü olmuştur. Ekserji veriminin bir fonksiyonu olan sürdürülebilirlik indeks (SI) değerleri kanatçıklı sistemlerde daha yüksektir.
\end{abstract}

Anahtar Kelimeler: Enerji, ekserji, kanatçık, PV/T kolektör, sürdürülebilirlik indeksi

\section{Sustainability Index and Thermodynamic Analysis of Porous Fin Added Air Heated PV/T Collector}

\begin{abstract}
As a result of using photovoltaic panels and solar collectors separately, both the installation cost and the usage area increase. Therefore researchers have directed from a single system to produce both heat and electricity. In this experimental study, a new type of fin air heated photovoltaic/thermal (PV/T) collector is designed and tested comparatively. In the experiments, natural and forced convection $\left(m_{1}=0.01 \mathrm{~kg} / \mathrm{s}\right.$ and $\left.m_{2}=0.015 \mathrm{~kg} / \mathrm{s}\right)$ was applied to $\mathrm{PV} / \mathrm{T}$ collectors with and without fins. The thermodynamic analysis of all systems and the sustainability index (SI), which is a function of exergy efficiency, were examined. According to the results obtained, the increase in mass flow rate and the integration of the fins had a positive effect on the output power, electrical energy and exergy of the PV / T system. The lowest output power in the system is $26.84 \mathrm{~W}$ in the natural convection and without fin (M1), and the highest output power is $37.40 \mathrm{~W}$ in the forced convection and with fin (M6). Comparing all PV/T collectors, the highest overall exergy efficiency is the M4 collector with natural convection and fins with $20.48 \%$. The sustainability index (SI) values, which are a function of exergy efficiency, are higher in finned systems.
\end{abstract}

Keywords: Energy, exergy, fins, PV/T collector, sustainability index

\section{GÍRIS}

Dünya nüfusunun her geçen gün artması ve sanayileşme ile birlikte dünyanın enerjiye olan talebi artmaktadır. Bununla birlikte enerji krizi birçok ülkede ekonomik büyümenin önünde bir engeldir. $\mathrm{Bu}$ sorunları çözmenin en etkili yollarından biri fosil yakıt tüketiminin azaltılarak yerine daha fazla yenilenebilir enerji sistemlerine yer verilmesidir. Ayrıca fosil yakıt ve türevlerinin kullanılması 


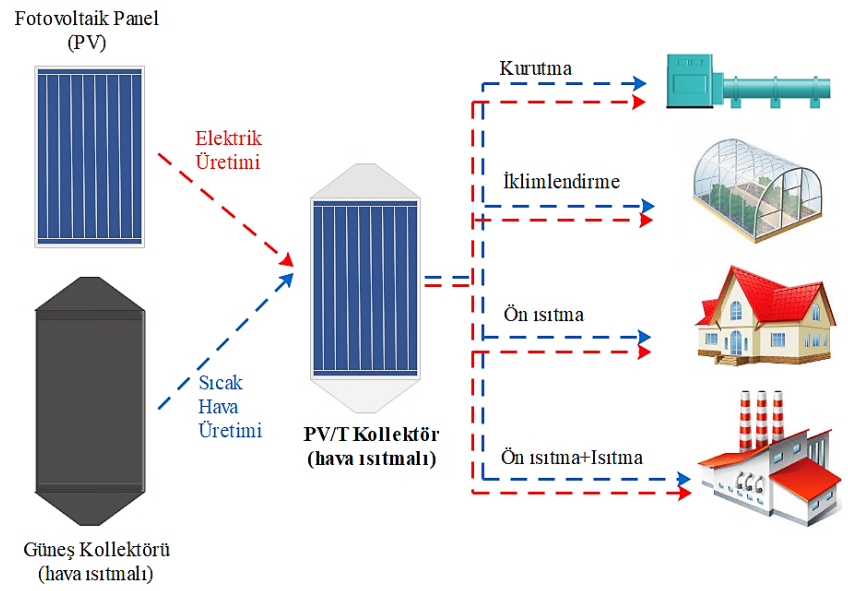

Şekil 1. PV/T kolektörü oluşturan parçalar ve kullanım alanları

ekosisteme ciddi bir şekilde zarar vererek küresel 1sınmaya neden olmaktadır. Yenilebilir enerji kaynakları arasında güneş enerjisi, rüzgar enerjisi, jeotermal enerji vb. yer almaktadır. Bu kaynaklar çevre dostu oldukları için hayati öneme sahiptirler. Güneş enerjisinden; fotovoltaik (PV) panelleri kullanarak elektrik enerjisinden, güneş kolektörlerini kullanarak termal enerjiden faydalanmak mümkündür. $\mathrm{Bu}$ iki farklı sistem ayrı ayrı kullanıldığından hem maliyet hem de kurulum alanının fazlalığ 1 gibi iki temel sorunla karşımıza çıkmaktadır. Bu sistemlerin her ikisinin de bir arada bulunduğu Fotovoltaik/Termal (PV/T) kolektörler kullanarak hem maliyetleri hem de kurulum alanı ihtiyaçlarını indirgeyebiliriz (Buonomano vd., 2013; Chow, 2010). Şekil 1'de PV ve güneş kolektörünün birleşimi olan PV/T kolektörü ve kullanım alanları verilmiştir.

Jia vd., (2019) çalışmalarında farklı çevresel koşullar ve farklı çalışma sıvıları kullanılarak oluşturulan $\mathrm{PV} / \mathrm{T}$ kolektörleri üzerine bir derleme araştırmasını özetlemişlerdir. Bu incelemenin amacı, farklı PV/T sistemleri için uygun çevresel koşulları ve uygulamaları tanımlamaktır. Joshi ve Tiwari, (2007) hava 1sıtmalı PV/T kolektörlerinin farklı iklim durumlarındaki termodinamik değerlerini incelemişlerdir. Bu kolektörlerin enerji verimi \%5565 arasında iken ekserji verimi \%12-15 arasında yer almıştır. Nayak ve Tiwari, (2008) seraya entegre edilmiş $\mathrm{PV} / \mathrm{T}$ sisteminin enerji ve ekserji analizini yapmışlardır. Sistemin ekserji verimliliğini \%4 olarak hesaplamışladır. Agrawal ve Tiwari, (2011) hibrit mikro kanallı PV/T kollektrönün genel enerjisini ve ekserjisini analiz etmişlerdir. Rajoria vd., (2012) hava 1sıtmalı PV/T kolektörlerinde hava girişinin ve çıkışının farklı konfigürasyonları için sistemlerin ekserji verimlerini incelemiş̧lerdir. Sistemlerin ekserji değerleri incelendiğinde en yüksek ekserji verimi \%12.9 olarak bulunmuştur. Sarhaddi vd., (2011) PV/T hava 1sıtmalı güneş kolektörünün optimum performansını ve tasarım parametrelerini belirlemek için matematiksel modelleme ile deneysel sonuçlarını karşılaştırmışladır. Giriş hava hızı ve güneş 1şınım yoğunluğunun artmasıyla ekserji veriminin arttığı belirtilmiştir. Kandilli, (2019) PV ve $\mathrm{PV} / \mathrm{T}$ sistemlerin çıkış performanslarını deneysel olarak araştırmıştır. PV ve PV/T sistemlerin elektriksel verimi yaklaşık $\% 11$ ve $\% 13$ olarak bulunurken ekserji verimleri yaklaşık \%12 ve \%14'tür. Fudholi vd., (2019) $\nabla$-oluklu soğurucuya sahip hava 1sıtmalı PV/T kolektörünün ekserji analizi ve sürdürülebilirlik indeksini deneysel ve teorik olarak çalışmışlardır. PV/T sisteminin ekserji verimini \%12.89, sürdürülebilirlik indeksini ise 1.148 bulmuşlardır. Fudholi vd., (2018) teorik ve deneysel çalışmalarını 300-1200 W/m² arasında değişen güneş 1şınım değerlerinde ve $0.007-0.07 \mathrm{~kg} / \mathrm{s}$ arasında değişen 5 farklı debide $\mathrm{PV} / \mathrm{T}$ kolektörlerin termodinamik değerlerini incelemişlerdir. PV/T sistemin en iyi ekserji verimi $0.038 \mathrm{~kg} / \mathrm{s}$ 'de $\% 12.92$ olarak bulmuşlardır. Abdullah vd., (2019) hava 1sıtmalı PV/T kolektörünü sayısal ve deneysel olarak araştırmışladır. Elde edilen sonuçlara göre sistemin termal verimi sayısal çalışmada yaklaşık \%20 iken deneysel çalışmada bu sonuç \%30'dur. Hava 1sıtmalı kanatçıklı PV/T sistem ile kanatçıksız PV/T sistemin çıkış parametreleri karşılaştırıldığında kanatçıklı sistemin elektrik, enerji ve ekserji verimlerinde ciddi artışların meydana geldiği Fan vd., (2018); Özakin ve Kaya, (2019) yazarları tarafından beyan edilmiştir. Özakın ve Kaya, (2020) çalışmalarında farklı malzeme ve konfigürasyonlarda kanatçıklar kullanılarak PV/T'nin elektriksel, 1s1 ve ekserji verimleri deneysel olarak araştırılmış, 1 sıl ve ekserji verimliliklerini etkileyen kontrol parametrelerinin optimizasyon analizi yapılmıştır. Hem monokristal hem de polikristal panellerde bakır, alüminyum ve pirinç malzemelerden yapılan kanatların sık ve seyrek konfigürasyonlarına göre deneyler yapılmış ve kanatsız (boş) durumla karşılaştııılmıştır. Hem sık hem de seyrek kanatçık konfigürasyonları için verimlilik değerleri, kanatsız duruma kıyasla önemli ölçüde artmıştır. Ayrıca, kanatçık malzemelerinin verim değerlerine olan en iyi etki sıralanışı bakır, alüminyum ve pirinç olarak belirtmişlerdir. 
PV panellerin verimini olumsuz yönde etkileyen faktörlerin en başında yüksek panel yüzey sıcaklığı gelmektedir. Bu negatif durumu en aza indirmek için hava ve poroz (alüminyum köpük) kanatçı kullanılarak PV panelin arka yüzeyinde oluşan atık 1S1 absorbe edilerek PV panelin verim değerleri ve sistemin yaşam ömrü deneysel olarak araştırılmıştır. Ayrıca, poroz kanatçik kullanılarak PV/T kolektörlerin performansı üzerindeki etkileri araştırıldığında literatürde kısıtlı sayıda çalışma bulunduğu ve bu konu üzerinde inceleme yapmak isteyen araştırmacılara faydalı olacağı düşünülmektedir.

\section{MATERYAL VE METOT}

Deneyler, Temmuz 2018'de Frrat Üniversitesi Teknoloji Fakültesi bahçesinde bulutsuz hava şartlarında gerçekleştirilmiştir. Çalışmanın birinci amacı, alüminyum köpük kanatçıklar kullanılarak doğal ve zorlanmış taşınım altında PV panelin yüzey sıcaklığını düşürmek ve PV/T kolektörün termal enerjinden faydalanabilmektir. İkinci amaç ise, doğal taşınım, zorlanmış taşınım ve kanatçık etkisinin PV/T sistemlerinin çıkış değerlerinden olan elektrik, termal, enerji ve ekserji verimlerine etkisi hesaplanırken sistemlerin sürdürülebilirlik indeksi incelenecektir.

Tablo 1. Deneylerde kullanılan PV panel, kanatçık ve termal macunun teknik özellikleri

\begin{tabular}{ll}
\hline Özellikler & Değerler \\
\hline PV panel & \\
Maksimum Güç $\left(P_{m a k}\right)$ & $50 \mathrm{~W}$ \\
Maksimum Güç Gerilimi $\left(V_{m p}\right)$ & $18.30 \mathrm{~V}$ \\
Maksimum Güç Akımı $\left(I_{m p}\right)$ & $2.75 \mathrm{~A}$ \\
Açı Devre Gerilimi $\left(V_{o c}\right)$ & $22.77 \mathrm{~V}$ \\
Kısa Devre Akımı $\left(I_{s c}\right)$ & $2.93 \mathrm{~A}$ \\
Çalışma Sicaklığı & $-40{ }^{\circ} \mathrm{C}+85^{\circ} \mathrm{C}$ \\
Sıcaklık Katsayısı $\left(P_{m}\right)$ & $-0.46 \% /{ }^{\circ} \mathrm{C}$ \\
Sıcaklık Katsayısı $\left(V_{o c}\right)$ & $-0.34 \% /{ }^{\circ}$ \\
Sıcaklık Katsayısı $\left(I_{s c}\right)$ & $0.045 \% /{ }^{\circ} \mathrm{C}$ \\
Boyutlar (mm) & $665 \times 520 x 25$ \\
Alüminyum köpük kanatçık & \\
Kimyasal bileşim & $\% 97 \mathrm{Al}$. \\
Hücre tipi & $\mathrm{Kapalı} \mathrm{hücre}$ \\
Yoğunluk & $0.2-0.4 \mathrm{~g} / \mathrm{cm}^{3}$ \\
Isıl iletkenlik & $0.268 \mathrm{~W} /(\mathrm{mK})$ \\
Termal iletken macun & \\
Termal iletkenlik & $8.5 \mathrm{~W} /(\mathrm{mK})$ \\
Viskozite & $87 \mathrm{~Pa} . \mathrm{s}$ \\
Yoğunluk & $2.5 \mathrm{~g} / \mathrm{cm}^{3}$ \\
\hline Kantç
\end{tabular}

Kanatçık seçerken kolay temin ve monte edilebilir olmasının yanında ucuz, hafif ve isı iletim katsayı değerinin yüksek olması gerekmektedir. Bu kriterlere göre deneylerde kapalı hücre yapısına sahip alüminyum köpük kanatçıklar seçilmiştir. Bir kanatçığın boyutları $5 \times 12 \mathrm{~cm}$ ve kalınlığ $1 \mathrm{~cm}$ 'dir. Kanatçıklı PV/T kollektörlerin (M4, M5 ve M6) her birinde 24 adet olacak şekilde toplamda 72 adet poroz kanatçık kullanılmıştır. Poroz kanatçıklar her bir güneş hücresinin ortasına gelecek şekilde PV panelin arkasına termal macun yardımıyla entegre edilmiştir. Termal macunun amacı, hava boşluklarını önleyerek kanatçık ile PV panel arasındaki termal temas direncini azaltmaktır. Deney sisteminde kullanılan PV panel, alüminyum gözenekli kanatçık ve termal iletken macunun teknik özellikleri Tablo 1'de verilmiștir.

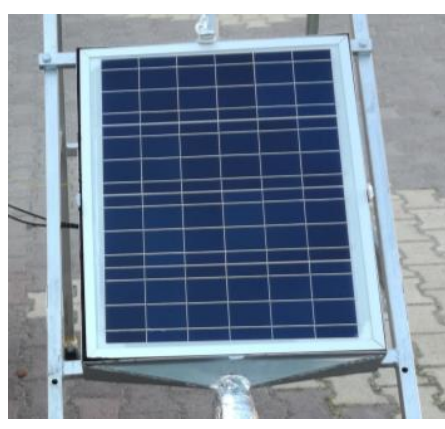

(a)

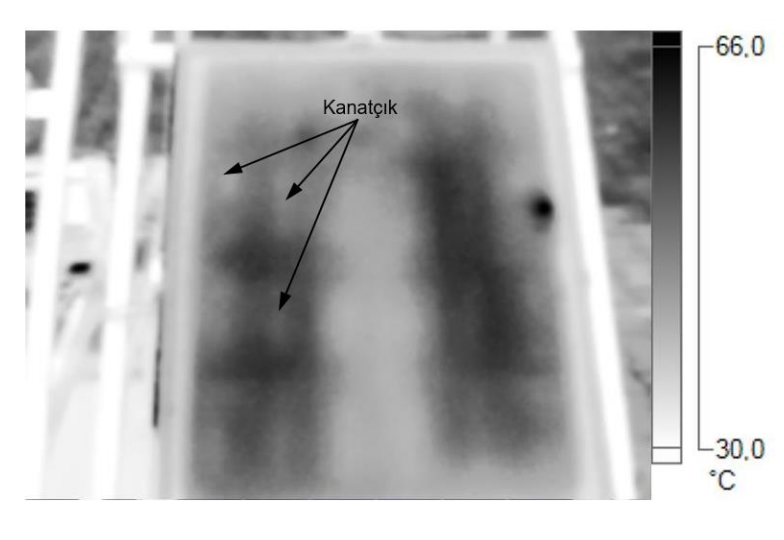

(c)

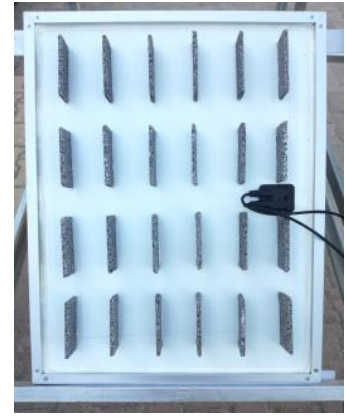

(b)
Şekil 2. (a) Deney seti (b) kanatçık yerleşimi (c) termal kamera görüntüsü

$\mathrm{PV} / \mathrm{T}$ kolektörlerinin giriş, çıkış, yüzey sıcaklıkları, çevre sıcaklıkları OMEGA marka T tipi 1sıl çift kullanılarak ölçülmüştür. Isıl çiftlerin çalışma sicaklık aralığ $1-200{ }^{\circ} \mathrm{C}$ ile $+300{ }^{\circ} \mathrm{C}$, hassasiyeti $\pm \% 0.5^{\prime}$ dir. Hassasiyeti $+40^{\circ} \mathrm{C}$ ile $+80^{\circ} \mathrm{C}$ arasinda $\% 10$ olan CMP3 model piranometre güneş 1şınım 
değerleri okumak için kullanılmıştır. DT-619 model ve hava hızı çözünürlüğü $0.1 \mathrm{~m} / \mathrm{s}$ olan anenometre ile rüzgar ölçümleri yapılmıştır. Deneylerdeki tüm değerler Keithley marka 2701 model 40 kanallı datalogger ile elde edilmiştir. PV/T kolektörü, kanatçıkların yerleşimi ve $\mathrm{PV} / \mathrm{T}$ kanatçıklı kolektörünün $0.01 \mathrm{~kg} / \mathrm{s}$ kütlesel debi altındaki termal kamera görüntüsü Şekil 2'de verilmiştir. Deneyler havanın bulutlu olmadığ 1 ardişık üç günde gerçekleştirilmiştir. İlk gün deney setleri ve ekipmanları test edilmiştir. İkinci ve üçüncü günlerde benzer çevre şartlarındaki $\mathrm{PV} / \mathrm{T}$ kolektörler test edilmiştir. İkinci günde kanatçıksız doğal ve zorlanmış taşınım altındaki PV/T kolektörler (M1, M2 ve M3), üçüncü gün ise poroz kanatçık ilave edilmiş PV/T kolektörlerin (M4, M5 ve M6) doğal ve zorlanmış taşınım altındaki sıcaklık, akım, gerilim, verim değerleri ile sürdürülebilirlik indeksi araştırılmıştır. Deneyleri gerçekleştirilen PV/T sistemlerinin kısaltması ve tanımlaması Tablo 2'de gösterilmiştir. PV/T sistemindeki havanın 1sınması ve deney setinin şematik gösterimi Şekil 3'te verilmiştir.

Tablo 2. PV/T kolektörlerinin tanımlanması

\begin{tabular}{ccc}
\hline PV/T kolektörler & Kanatçık & $\begin{array}{c}\text { Debi } \\
\text { (kg/s) }\end{array}$ \\
\hline M1 & Yok & DT \\
M2 & Yok & 0.01 \\
M3 & Yok & 0.015 \\
M4 & Var & DT \\
M5 & Var & 0.01 \\
M6 & Var & 0.015 \\
\hline
\end{tabular}

\section{Enerji Analizi}

Bir PV/T kolektörünün sistem performans1 termal ve elektriksel verimliliklerinin toplamı olarak gösterilmektedir. PV/T kolektörlerinin toplam performansını belirlemek veya ifade etmek için genel verimlilik ifadesi kullanılır ve aşağıdaki eşitlikten yararlanılır (Hossain vd., 2019; Joe vd., 2015).

$\eta_{I, p v / t}=\eta_{t e r m}+\eta_{e l}$

PV/T kolektörünün 1sıl verimi aşağıdaki formülle hesaplanır (Arslan vd., 2020; Hossain vd., 2019):

$\eta_{\text {term }}=\frac{\dot{Q}_{u}}{I_{s} A}$

Bu eşitlikteki $\dot{Q}_{u}$ ise
$\dot{Q}_{u}=\dot{m} c_{p}\left(T_{c}-T_{g}\right)$

veya

$\dot{Q}_{u}=h_{c a} A\left(T_{h}-T_{\varsigma}\right)$

$h_{c a}=5.7+3.8 v$

şeklinde yazılabilir. Bir PV panelin enerji dönüşüm verimliliğii, dönüştürülen ve geri kazanılan enerjinin yüzdesi olarak ifade edilir (Bayrak vd., 2017).

$\eta_{e l}=\frac{P_{m a k}}{I_{s} A}$

Sistemin maksimum çıkış gücünü hesaplamak için Eşitlik (7) kullanılabilir.

$P_{\text {mak }}=I_{m a k} V_{m a k}$

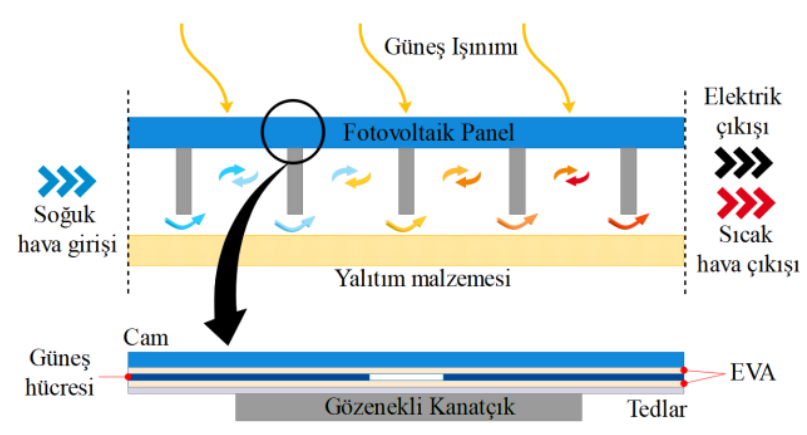

(a)

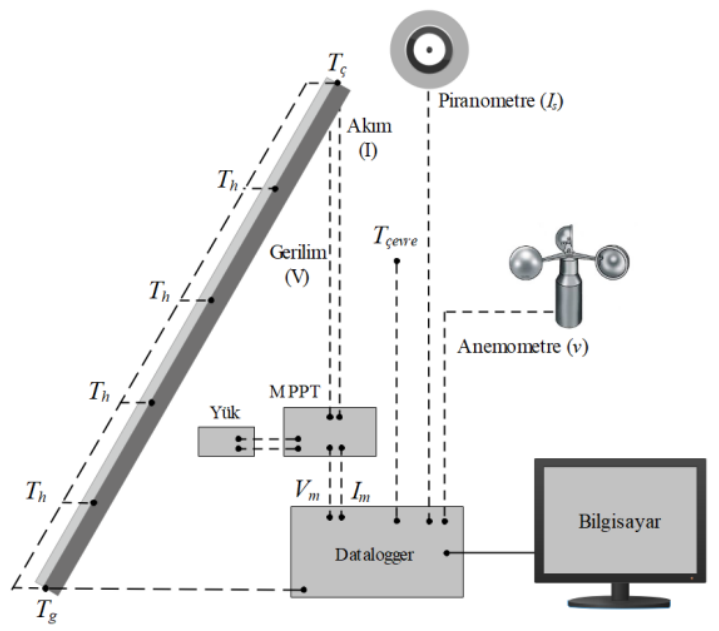

(b)

Şekil 3. Şematik gösterim (a) PV/T kolektör (b) Deney seti

\section{Enerji Analizi}


Bir PV/T kolektörünün sistem performans termal ve elektriksel verimliliklerinin toplamı olarak gösterilmektedir. PV/T kolektörlerinin toplam performansını belirlemek veya ifade etmek için genel verimlilik ifadesi kullanılır ve aşağıdaki eşitlikten yararlanılır (Hossain vd., 2019; Joe vd., 2015).

$\eta_{I, p v / t}=\eta_{\text {term }}+\eta_{e l}$

PV/T kolektörünün ısıl verimi aşağıdaki formülle hesaplanır (Arslan vd., 2020; Hossain vd., 2019):

$\eta_{\text {term }}=\frac{\dot{Q}_{u}}{I_{s} A}$

Bu eşitlikteki $\dot{Q}_{u}$ ise

$\dot{Q}_{u}=\dot{m} c_{p}\left(T_{c}-T_{g}\right)$

veya

$\dot{Q}_{u}=h_{c a} A\left(T_{h}-T_{c}\right)$

$h_{c a}=5.7+3.8 v$

şeklinde yazılabilir. Bir PV panelin enerji dönüşüm verimliliğii, dönüştürülen ve geri kazanılan enerjinin yüzdesi olarak ifade edilir (Bayrak vd., 2017).

$\eta_{e l}=\frac{P_{m a k}}{I_{s} A}$

Sistemin maksimum çıkış gücünü hesaplamak için Eşitlik (7) kullanılabilir.

$$
P_{m a k}=I_{m a k} V_{m a k}
$$

\section{Ekserji analizi}

Enerji analizi, sistemler için yalnızca nicel bir analiz sağlar ve bir sistemin performansı hakkında kesin bir sonuca varmak için tek başına yeterli değildir. $\mathrm{Bu}$ yüzden enerji sistemlerinin ekserji analizi yapılarak enerjinin nicel ve nitel bir analizini sağlanmış olur. Ekserji, PV/T kolektöründen sağlanabilecek en yüksek kullanım potansiyelidir ve enerjinin kalitesine karşılık gelir. PV/T sistemin ekserji verimliliği (Bayrak and Oztop 2020; Hepbasli 2008; Petela 2008);
$\eta_{I I, p v / t}=\frac{E x_{\zeta}}{E x_{g}}$

çıkış ekserjisinin giriş ekserjisine oranı olarak tanımlanır. Eşitlik (9)'de PV/T sisteminin giriş ekserjisi ifade etmektedir.

$$
E x_{g}=I_{s} A\left[1-\frac{4}{3}\left(\frac{T_{c}}{T_{s}}\right)+\frac{1}{3}\left(\frac{T_{c}}{T_{s}}\right)^{4}\right]
$$

Buradaki $T_{c}$ ve $T_{s}$ sirasiyla çevre ve güneş sıcaklıklanıdır (K). Güneş sıcaklığı 5777 K alınmıştır. Sistemin çıkış ekserjisi, termal ve elektrik ekserjilerini içermektedir (Bayrak vd., 2019; Sukumaran ve Sudhakar, 2018).

$$
E x_{\varsigma}=E x_{t e r m}+E x_{e l}
$$

$\mathrm{PV} / \mathrm{T}$ sisteminin termal ve elektrik ekserjileri (Arslan vd., 2020; Bayrak vd., 2020, 2017a)

$E x_{\text {term }}=Q\left(1-\frac{T_{c}}{T_{h}}\right)$

$E x_{e l}=I_{m a k} V_{m a k}=P_{m a k}$

eşitliklerinden faydalanarak hesaplayabiliriz. Eşitlik (11)'deki $Q$ çevreye yayılan ısıdır. Toplam 1sı kaybı katsayısı $(U)$, taşınım ve ışınımdan kaynaklı kayıpları içermekte olup aşağıdaki eşitlikler kullanılarak hesaplanmaktadır. (Arslan vd., 2020; Hossain vd., 2019; Shukla vd., 2015)

$$
Q=U A\left(T_{h}-T_{c}\right)
$$

$U=h_{\text {conv }}+h_{\text {rad }}$

$h_{\text {conv }}=2.8+3 v$

$h_{r a d}=\varepsilon \sigma\left(T_{s k y}+T_{h}\right)\left(T_{s k y}^{2}+T_{h}^{2}\right)$

$T_{s k y}=0.0552\left(T_{c}\right)^{1,5}$

Kaynakların verimli ve etkin kullanımı için bir sürdürülebilirlik analizine ihtiyaç duyulmaktadır. Sürdürülebilirlik indeksi (SI) gibi ekserji 
sürdürülebilirlik göstergeleri, belirli bir ekserji girdisi için bir süreçteki tersinmezlikleri ve ekserji kayıplarını ele alır. Termodinamik performans, bu göstergeler aracılığıyla daha iyi değerlendirilebilir. Ekserji kayıpları arttıkça, SI azalmaktadır. Başka bir deyişle SI, sistemin ömrünü açıklar ve aşağıdaki gibi açıklanabilir (Bayrak vd., 2013; Mugi ve Chandramohan, 2021; Oztop vd., 2013).

$$
S I=\frac{1}{1-\eta_{I I}}
$$

\section{Belirsizlik analizi}

Holman (Holman, J.P., 1994) tarafindan açıklanan yöntem kullanılarak bir belirsizlik analizi sisteme uygulanmıştır. Deneylerde, $n$ bağımsız parametrenin $\left(x_{1}, x_{2}, \ldots \ldots \ldots \ldots x_{n}\right)$ ölçülen değerlerini, $(R)$ ise etkin parametreleri tanımlanır. Her bağımsız değişken ve hesaplanan değişkenler için hata oranı $W_{l}, W_{2}, \ldots \ldots \ldots W_{n}$ olarak elde edilir. Ayrıca $W, R$ 'nin hata oranı olarak tanımlanır. Tablo 3'de ölçülen değerlerin belirsizlik analizi verilmiştir.

$W_{R}=\left[\left(\frac{\partial R}{\partial x_{1}} W_{1}\right)^{2}+\left(\frac{\partial R}{\partial x_{2}} W_{2}\right)^{2}+\ldots . .+\left(\frac{\partial R}{\partial x_{n}} W_{n}\right)^{2}\right]^{1 / 2}$

Tablo 3. Ölçülen değerlerin belirsizlik analizi

\begin{tabular}{lcc}
\hline Değişkenler & Birim & Sonuçlar \\
\hline Çevre sıcaklığg1 & ${ }^{\circ} \mathrm{C}$ & \pm 1.05 \\
PV panel sıcaklığ1 & ${ }^{\circ} \mathrm{C}$ & \pm 1.15 \\
Rüzgar hızı & $\mathrm{ms}^{-1}$ & \pm 0.21 \\
Güneş 1şınımı & $\mathrm{Wm}^{-2}$ & \pm 0.09 \\
PV güç & $\mathrm{W}$ & \pm 0.82 \\
\hline
\end{tabular}

\section{TARTIŞMA VE SONUÇ}

Termodinamiğin birinci yasasına dayanan enerji analizi, girdi enerjisinin nasıl kullanıldığını ve enerji tüketimine en çok katkıda bulunan sistemlerin hangileri olduğunu gösteren özet bir tablo sunmaktadır. $\mathrm{Bu}$ çalıșmada ilk olarak, PV/T kolektörlerinin elektrik çıkış gücü, elektrik verimliliği, termal verimlilik gibi farklı enerji parametrelerindeki değişimi, güneş 1şınımı, hücre sıcaklığı, kanatçığın ve kütlesel debinin bir fonksiyonu olarak analiz edilerek bunlardan hangilerinin $\mathrm{PV} / \mathrm{T}$ sistemlerinin enerji performans1 üzerinde belirgin etkisinin olduğu incelenmiştir. Deneyler, havanın bulutlu olmadığı ardıșık üç günde gerçekleştirilmiştir. Günler arasındaki en yükssek sıcaklık fark1 $1{ }^{\circ} \mathrm{C}$, en yüksek 1şınım farkı $7 \mathrm{~W} / \mathrm{m}^{2}$ olarak ölçülmüștür.
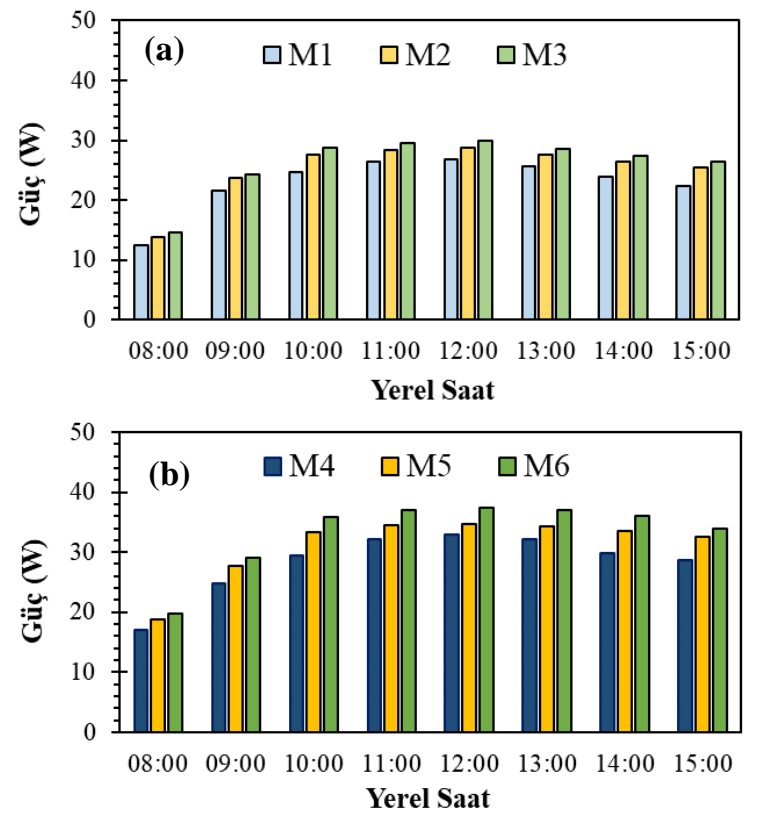

Şekil 4. $P V / T$ sistemlerinin çıkış güçlerinin değişimi (a) kanatçıksız (b) kanatçıklı

Şekil 4 (a ve b)'te kanatçıklı ve kanatçıksız PV/T kolektörlerinin doğal ve zorlanmış taşınım durumlarında elde edilen çıkış güçlerinin zamana karşı değişimi verilmiştir. Kanatçıklı ve kanatçıksız sistemlerde kütlesel debinin artmasıyla ya da soğutma etkisiyle çıkış gücünde artış meydana gelmiştir. Kanatçıksız sistemlerde (M1, M2 ve M3) en yüksek çıkış güçleri sırasıyla $26.84 \mathrm{~W}, 28.81 \mathrm{~W}, 29.9 \mathrm{~W}$, kanatçıklı sistemlerde (M4, M5 ve M6) en yüksek çıkış güçleri sırasıyla $32.88 \mathrm{~W}, 34.71 \mathrm{~W}, 37.40 \mathrm{~W}$ 'tır.

Şekil 5'de yer alan eğriler kanatçıklı ve kanatçıksız PV/T kolektörlerinin elektriksel ve termal verim değerlerinin zamana göre değişimini ifade etmektedir. Şekil 5'de dolgu göstergeli ve düz çizgili eğriler (mavi ok ile gösterilmiştir) PV/T kolektörlerin elektriksel verimlerini, dolgusuz ve kesik çizgili eğriler ise (kırmızı ok ile gösterilmiştir) termal verimleri göstermektedir. Şekil 5 (a)'da kanatçıksız sistemlerin verim değişimleri görülmekte olup kütlesel debi değeri artıkça elektrik verimi artmıș, termal verimde dalgalanmalar meydana gelmiştir. Zorlanmış taşınımdaki kütlesel debi etkisi panel yüzeyinin soğumasına neden olarak elektrik verimine pozitif etki göstermiş, termal verimde ise olumlu etki göstermemiştir. Şekil 5 (b)'de ise kanatçıklı PV/T sisteminin verim değerlerinin değişimi verilmiştir. 
Kanatçıklı ve kanatçıksız sistemlerin verim değerleri karşılaştırıldığında kanatçıklı sistemlerin daha yüksek olduğu görülmektedir. Kanatçıksız PV/T kolektörlerinin (M1, M2 ve M3) elektriksel verimleri sırasıyla \%8.34, \%9.07, \%9.51, kanatçıklı PV/T kolektörlerinin (M4, M5 ve M6) elektriksel verimleri sırasıyla \%10.27, \%11.12, \%12'dir. Kanatçıksız $\mathrm{PV} / \mathrm{T}$ kolektörlerinin termal verimleri sirasiyla \%16.48, \%15.59, \%13.85, kanatçıklı PV/T kolektörlerinin termal verimleri sirasıly $\% 17.28$, $\% 15.96, \% 14.62$ 'dir.

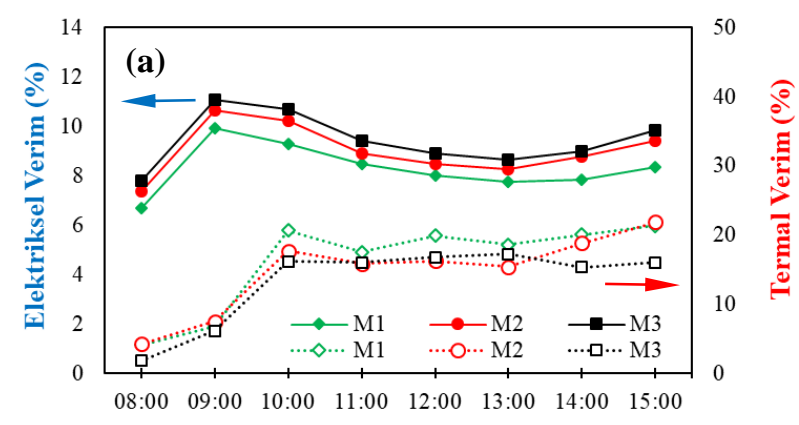

Yerel Saat

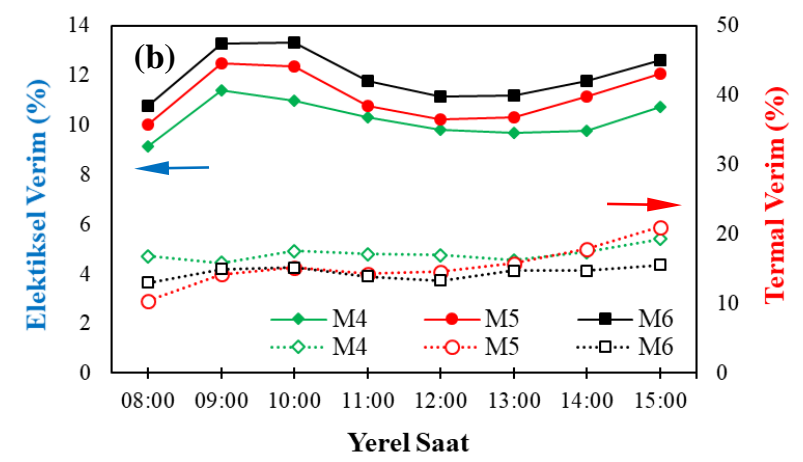

Şekil 5. PV/T sistemlerinin elektriksel ve termal verimlerinin değişimi (a) kanatçıksız (b) kanatçıklı

Şekil 6 (a)'da PV/T kolektörlerinin elektriksel ve termal ekserji değerleri verilmiştir. Elektrik ekserji hem kanatçık uygulamasında hem de doğal taşınımdan zorlanmış taşınıma geçmesi ile birlikte artmaktadır. PV/T kolektörlerinin elektriksel ekserji değerleri sirasiyla $23.47 \mathrm{~W}, 25.70 \mathrm{~W}, 26.73 \mathrm{~W}$, $28.86 \mathrm{~W}, 32.58 \mathrm{~W}$ ve $33.90 \mathrm{~W}$ 'tır. Termal ekserji değerlerinde ise zorlanmış taşınımın kütlesel debinin etkisiyle kanatçıklı ve kanatçıksız sistemlerde düşüş yaşanmıştır. Şekil 6 (b)'de PV/T sistemlerinin ekserji verimlerinin ortalama değerleri verilmiştir. Doğal ve zorlanmış taşınımlarda kanatçıklı sistemlerin genel ekserji verimi kanatçıksız sistemin genel ekserji veriminden daha yüksek çıkmıştır. Doğal taşınımın uygulandığ1 (M1 ve M4) sistemlerinde $\% 5.65, \dot{m}_{1}$ kütlesel debisindeki (M2 ve M5) sistemlerinde $\% 8.89, \quad \dot{m}_{2}$ kütlesel debisindeki (M3 ve M6) sistemlerinde \%11.37 ekserji verim artış1 sağlanmıştır. Şekil 6 (c)'de PV/T sistemlerinin Sürdürülebilirlik İndeksi (SI) gösterilmiştir. Ekserji kayıpları azaldıkça Sürdürülebilirlik İndeksi artmaktadır. Buna göre, kanatçıklı sistemlerin kanatçıksız sistemlere göre SI yüksek çıkmaktadır. En yüksek SI artış oranı ise M3 ve M6 arasında oluşmuş̧tur.
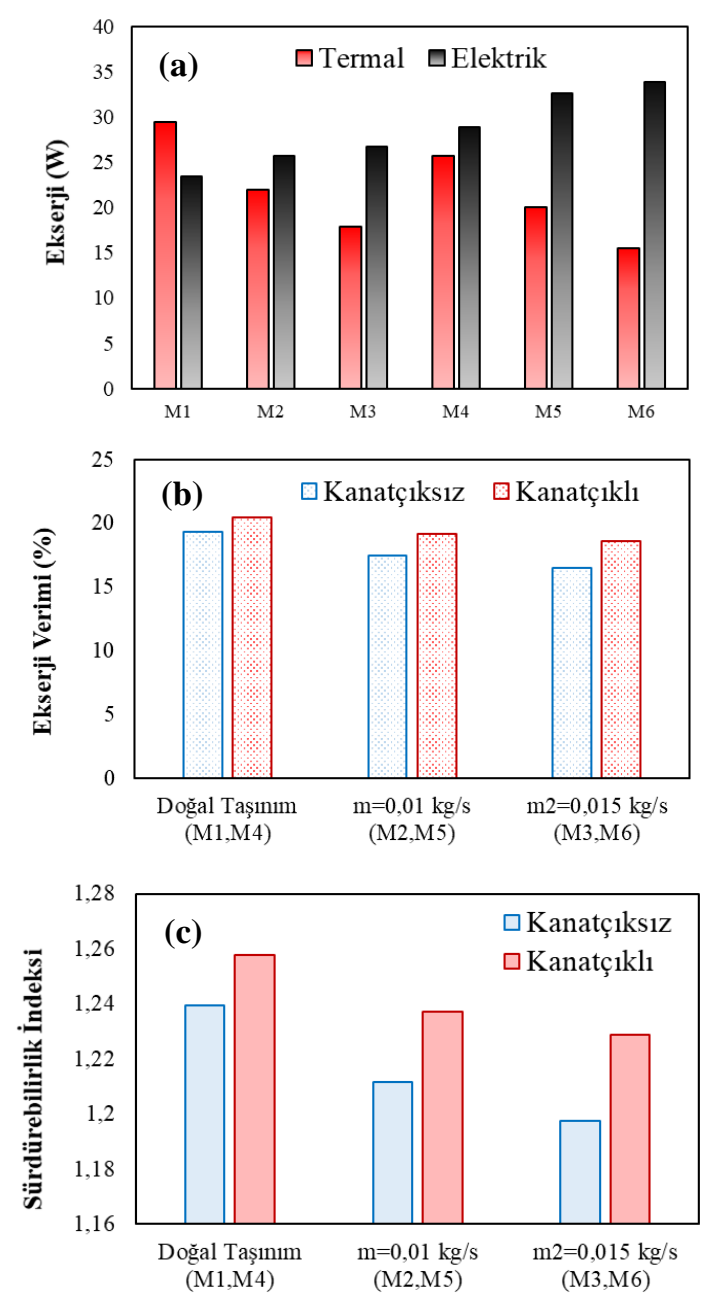

Şekil 6. PV/T sistemlerin (a) Ortalama elektriksel ve termal ekserji değerleri (b) PV/T sistemlerin ekserji verimleri (c) Sürdürülebilirlik İndeksi

\section{SONUÇLAR}

$\mathrm{Bu}$ çalışmada hava 1sıtmalı PV/T kolektörü ile gözenekli alüminyum kanatçık entegre edilmiş hava 1sıtmalı PV/T kolektörlerinin doğal ve zorlanmış 
taşınım $\left(\dot{m}_{1}=0.01 \mathrm{~kg} / \mathrm{s}\right.$ ve $\left.\dot{m}_{2}=0.015 \mathrm{~kg} / \mathrm{s}\right)$ altında termodinamik analizi ve sürdürülebilirlik indeksi incelenmiştir. Buna göre aşağıdaki sonuçlar s1ralanabilir;

a) Is1 iletim hızı maddenin türüne, kesit alanına, ısının iletildiği uçlar arasındaki sıcaklık farkına ve maddenin kalınlığına bağlı olduğu göz önünde bulundurulursa bu çalışmada seçilen poroz kanatçık PV/T sistemindeki PV panelde oluşan atık 1sının uzaklaştırılmasında pozitif etki etmiştir.

b) Kanatçık ilave edilmesi ve kütlesel debinin artması tüm sistemlerin elektriksel verimlere pozitif etki etmiştir.

c) PV/T kolektörde, PV panelin arka yüzeyine entegre edilen poroz kanatçıklar tüm sistemlerde (M1-M6) çıkış gücünün artmasına neden olmuştur. Ayrıca, sistemdeki kütlesel debinin artmasıyla da çıkış güçlerinde artış meydana gelmiştir. Sistemdeki en düşük çıkış gücü kanatçıksız ve doğal taşınımda (M1) 26.84W, en yüksek çıkış gücü kanatçıklı ve zorlanmış taşınımda (M6) 37.40W'tır.

d) Tüm PV/T kolektörleri karşılaştırıldığında en yüksek genel ekserji verimi \%20.48 ile doğal taşınımlı ve kanatçıklı M4 kolektörü olmuştur.

e) En yüksek enerji verimi kanatçıklı M6 deneyinden elde edilmiştir.

f) Tüm sistemlerin ekserji verimleri değerlendirildiğinde kanatçık ilavesi sisteme pozitif etki etmiştir.

g) Kanatçıklı sistemlerin ekserji verimi kanatçıksız sistemlere göre daha iyi olduğundan sürdürülebilirlik indeksi daha yüksek çıkmaktadır.

\section{Semboller ve Kisaltmalar}

A kolektörün alanı $\left(\mathrm{m}^{2}\right)$

$c_{p} \quad$ özgül hava 1sısı $(\mathrm{J} / \mathrm{kgK})$

Ex ekserji (W)

$h_{c a} \quad 1 \mathrm{~s} 1$ transfer katsayıs $\left(\mathrm{W} / \mathrm{m}^{2} \mathrm{~K}\right)$

I $\operatorname{akım(A)}$

$I_{s}$ güneş 1 şınımı $\left(\mathrm{W} / \mathrm{m}^{2}\right)$

$P$ güç (W)

$T \quad$ sicaklik $\left({ }^{\circ} \mathrm{C}\right)$

$V \quad$ gerilim $(\mathrm{V})$

$v \quad$ rüzgar hızı $(\mathrm{m} / \mathrm{s})$

$\dot{Q}_{u} \quad$ yararli enerji (W)

$\begin{array}{ll}\dot{m} & \text { kütlesel debi }(\mathrm{kg} / \mathrm{s}) \\ \eta_{I} & \text { enerji verimi } \\ \eta_{I I} & \text { ekserji verimi } \\ c ̧ & \text { çıkış } \\ D T & \text { doğal taşınım } \\ e l & \text { elektrik } \\ g & \text { giriş } \\ p v / t & \text { fotovoltaik/termal } \\ S I & \text { sürdürülebilirlik indeksi } \\ \text { term } & \text { termal }\end{array}$

\section{ÇIKAR ÇATIŞMASI BEYANI}

Yazar bu makale ile ilgili herhangi bir çıkar çatışması bildirmemektedir.

\section{ARAŞTIRMA VE YAYIN ETÍĞİ BEYANI}

Yazar/Yazarlar bu çalışmanın araştırma ve yayın etiğine uygun olduğunu beyan eder.

\section{KAYNAKLAR}

Abdullah, A. L., Misha, S., Tamaldin, N., Rosli, M. A. M., and Sachit, F. A. 2019. "Numerical Analysis of Solar Hybrid Photovoltaic Thermal Air Collector Simulation by ANSYS." CFD Letters 11(2):1-11.

Agrawal, S., and Tiwari, G. N. 2011. "Energy and Exergy Analysis of Hybrid Micro-Channel Photovoltaic Thermal Module.” Solar Energy 85(2):356-70. doi: 10.1016/j.solener.2010.11.013.

Arslan, E., Aktaş, M., and Can, Ö. F. 2020. "Experimental and Numerical Investigation of a Novel Photovoltaic Thermal (PV/T) Collector with the Energy and Exergy Analysis." Journal of Cleaner Production 276:123255. doi: 10.1016/j.jclepro.2020.123255.

Bayrak, F., Oztop, H. F., and Hepbasli, A. 2013. "Energy and Exergy Analyses of Porous Baffles Inserted Solar Air Heaters for Building Applications.” Energy and Buildings $57 . \quad$ doi: 10.1016/j.enbuild.2012.10.055.

Bayrak, F., Abu-Hamdeh, N., Alnefaie, K. A., and Öztop, H. F. 2017. "A Review on Exergy Analysis of Solar Electricity Production." Renewable and Sustainable Energy Reviews 74:755-70. doi: 10.1016/j.rser.2017.03.012.

Bayrak, F., Ertürk, G., and Oztop, H. F. 2017. "Effects of Partial Shading on Energy and Exergy Efficiencies for Photovoltaic Panels." Journal of Cleaner Production 164:58-69. doi: 10.1016/j.jclepro.2017.06.108.

Bayrak, F., and Oztop, H. F. 2020. "Effects of Static and Dynamic Shading on Thermodynamic and Electrical 
Performance for Photovoltaic Panels." Applied Thermal Engineering 169(December 2019):114900. doi: 10.1016/j.applthermaleng.2020.114900.

Bayrak, F., Oztop, H. F., and Selimefendigil, F. 2019. "Effects of Different Fin Parameters on Temperature and Efficiency for Cooling of Photovoltaic Panels under Natural Convection." Solar Energy 188:48494. doi: 10.1016/j.solener.2019.06.036.

Bayrak, F., Oztop, H. F., and Selimefendigil, F. 2020. "Experimental Study for the Application of Different Cooling Techniques in Photovoltaic (PV) Panels." Energy Conversion and Management 212(February):112789. doi: 10.1016/j.enconman.2020.112789.

Buonomano, A., Calise, F., Dentice d'Accadia, M., and Vanoli, L. 2013. "A Novel Solar Trigeneration System Based on Concentrating Photovoltaic/Thermal Collectors. Part 1: Design and Simulation Model." Energy 61:59-71. doi: 10.1016/j.energy.2013.02.009.

Chow, T. T. 2010. "A Review on Photovoltaic/Thermal Hybrid Solar Technology." Applied Energy 87(2):365-79. doi: 10.1016/j.apenergy.2009.06.037.

Fan, W., Kokogiannakis, G., and Ma, Z. 2018. "A MultiObjective Design Optimisation Strategy for Hybrid Photovoltaic Thermal Collector (PVT)-Solar Air Heater (SAH) Systems with Fins." Solar Energy 163(February):315-28. 10.1016/j.solener.2018.02.014.

Fudholi, A., Zohri, M., Jin, G. L., Ibrahim, A., Yen, C. H., Othman, M. Y., Ruslan, M. H., and Sopian, K. 2018. "Energy and Exergy Analyses of Photovoltaic Thermal Collector with $\nabla$-Groove." Solar Energy 159(November 2016):742-50. doi: 10.1016/j.solener.2017.11.056.

Fudholi, A., Zohri, M., Rukman, N. S. B., Nazri, N. S., Mustapha, M., Yen, C. H., Mohammad, M., and Sopian, K. 2019. "Exergy and Sustainability Index of Photovoltaic Thermal (PVT) Air Collector: A Theoretical and Experimental Study." Renewable and Sustainable Energy Reviews 100(July 2018):4451. doi: 10.1016/j.rser.2018.10.019.

Hepbasli, A. 2008. “A Key Review on Exergetic Analysis and Assessment of Renewable Energy Resources for a Sustainable Future." Renewable and Sustainable Energy Reviews 12(3):593-661. doi: 10.1016/j.rser.2006.10.001.

Holman, J.P, 1994. Experimental methods for engineers, 6th ed. Singapore: McGraw Hill.

Hossain, M. S., Pandey, A. K., Selvaraj, J., Abd Rahim, N., Rivai, A., and Tyagi, V. V. 2019. "Thermal Performance Analysis of Parallel Serpentine Flow Based Photovoltaic/Thermal (PV/T) System under Composite Climate of Malaysia." Applied Thermal Engineering 153(January):861-71. doi: 10.1016/j.applthermaleng.2019.01.007.
Jia, Y., Alva, G., and Fang, G. 2019. "Development and Applications of Photovoltaic-Thermal Systems: A Review." Renewable and Sustainable Energy Reviews 102(November 2018):249-65. doi: 10.1016/j.rser.2018.12.030.

Joe, J., Iniyan, S., and Goic, R. 2015. "Flat Plate Solar Photovoltaic - Thermal ( PV / T ) Systems : A Reference Guide." Renewable and Sustainable Energy Reviews 51:62-88. doi: 10.1016/j.rser.2015.06.022.

Joshi, A. S., and Tiwari, A. 2007. "Energy and Exergy Efficiencies of a Hybrid Photovoltaic-Thermal (PV/T) Air Collector." Renewable Energy 32(13):2223-41. doi: 10.1016/j.renene.2006.11.013.

Kandilli, C. 2019. "A Comparative Study on the EnergeticExergetic and Economical Performance of a Photovoltaic Thermal System (PVT)." Research on Engineering Structures and Materials (1):75-89. doi: 10.17515/resm2019.90en0117.

Mugi, V. R., and Chandramohan, V. P. 2021. "Energy and Exergy Analysis of Forced and Natural Convection Indirect Solar Dryers: Estimation of Exergy Inflow, Outflow, Losses, Exergy Efficiencies and Sustainability Indicators from Drying Experiments." Journal of Cleaner Production 282:124421. doi: 10.1016/j.jclepro.2020.124421.

Nayak, S., and Tiwari, G. N. 2008. "Energy and Exergy Analysis of Photovoltaic/Thermal Integrated with a Solar Greenhouse." Energy and Buildings 40(11):2015-21.

doi: 10.1016/j.enbuild.2008.05.007.

Özakin, A. N., and Kaya, F. 2019. "Effect on the Exergy of the PVT System of Fins Added to an Air-Cooled Channel: A Study on Temperature and Air Velocity with ANSYS Fluent." Solar Energy 184(December 2018):561-69. doi: 10.1016/j.solener.2019.03.100.

Özakın, A. N., and Kaya, F. 2020. "Experimental Thermodynamic Analysis of Air-Based PVT System Using Fins in Different Materials: Optimization of Control Parameters by Taguchi Method and ANOVA.” Solar Energy 197(September 2019):199211. doi: 10.1016/j.solener.2019.12.077.

Oztop, H. F., Bayrak, F., and Hepbasli, A. 2013. "Energetic and Exergetic Aspects of Solar Air Heating (Solar Collector) Systems." Renewable and Sustainable Energy Reviews 21. doi: 10.1016/j.rser.2012.12.019.

Petela, R. 2008. "An Approach to the Exergy Analysis of Photosynthesis." Solar Energy 82(4):311-28. doi: 10.1016/j.solener.2007.09.002.

Rajoria, C. S., Agrawal, S., and Tiwari, G. N. 2012. "Overall Thermal Energy and Exergy Analysis of Hybrid Photovoltaic Thermal Array." Solar Energy 86(5):1531-38. doi: 10.1016/j.solener.2012.02.014.

Sarhaddi, F., Farahat, S., Ajam, H., and Behzadmehr, A. 2011. "Exergetic Optimization of a Solar Photovoltaic Thermal (PV/T) Air Collector." 
International Journal of Energy Research 35(9):813-27. doi: 10.1002/er.1727.

Shukla, A., Khare, M., and Shukla, K. N. 2015. "Experimental Exergetic Performance Evaluation of Solar PV Module." International Journal of Scientific and Research Publications 5(1):1-9.

Sukumaran, S., and Sudhakar, K. 2018. "Performance Analysis of Solar Powered Airport Based on Energy and Exergy Analysis." Energy 149:1000-1009. doi: 10.1016/j.energy.2018.02.095. 